\title{
Influence of Activated Carbon Particles on Intermetallic Compound Growth Mechanism in Sn-Cu-Ni Composite Solder
}

\author{
M.I.I. Ramli ${ }^{1,}{ }^{*}$, M.A.A. Mohd Salleh ${ }^{1}$, M.N. Derman ${ }^{1}$, R.M. Said ${ }^{1}$ and N. Saud ${ }^{1}$. \\ ${ }^{1}$ Center of Excellence Geopolymer \& Green Technology (CeGeoGTech), School of Materials \\ Engineering, Universiti Malaysia Perlis (UniMAP), Taman Muhibbah, 02600 Jejawi, Arau, Perlis, \\ Malaysia.
}

\begin{abstract}
The influence of Activated Carbon (AC) particles on mechanical properties of $\mathrm{Sn}-\mathrm{Cu}-\mathrm{Ni}$-xAC solder joint was investigated. Five different Activated Carbon (AC) percentage addition ( 0 wt. \%, 0.25 wt. \%, 0.5 wt. $\%, 0.75$ wt. $\%$, and 1.0 wt. $\%$ ) were prepared via powder metallurgy (PM) technique. Interfacial IMC thickness measurement and shear strength results showed that with thinner IMC layer (by increasing amount of wt.\% of AC), the higher the shear strength of the joint. It is believed that the AC particles suppresses the interfacial IMC growth and thus improves the shear strength.
\end{abstract}

\section{Introduction}

The eutectic $\mathrm{Sn}-0.7 \mathrm{Cu}$ solder alloy has been used as one of the candidates to replace the traditional $\mathrm{Sn}-\mathrm{Pb}$ solder. However, $\mathrm{Sn}-0.7 \mathrm{Cu}$ has been reported to have poor mechanical properties and wettability compared to lead free solder alloys containing silver (Ag) [1]. Because of that, a small amount of nickel (Ni) were added into $\mathrm{Sn}-0.7 \mathrm{Cu}$ solder and has improved the fluidity of $\mathrm{Sn}-0.7 \mathrm{Cu}$ alloy [2]. As a result, $\mathrm{Sn}-\mathrm{Cu}-\mathrm{Ni}$ solder alloy is also considered as a low cost solder alloy which has an equal attractive as $\mathrm{Sn}-\mathrm{Pb}$ solder for wave, iron and reflow soldering process [3].

The fast changing technology and increasing miniaturization of electronic devices place challenges for obtaining successful component joint. Therefore, solder with improved mechanical properties have to be developed to suit with rapid advance in the electronics industry. By these reasons, many researchers investigate and develop a solder material to meet the requirement of the modern solder. Some attractive and potentially available methods of enhancing solder joint performances are by adding reinforcements to solder alloys, to form composite solders [4]. In general, composite solder should improve the mechanical properties of a solder joint.

Major studies have proven that composite technology improves the reliability of solder joints. Ceramic reinforcement particles has been developed by Nai et al. [5] by using titanium diboride $\left(\mathrm{TiB}_{2}\right)$ and multi walled carbon nanotubes (MWCNTs). They reported

\footnotetext{
* Corresponding author : mohdizrulizwan@gmail.com
} 
that mechanical properties of both composites had majorly improved. Other ceramic reinforcing material such as $\mathrm{Si}_{3} \mathrm{~N}_{4}$ has also been studied by Ramli et al. [6] and Mohd Salleh et al. [7]. They also reported that the mechanical properties of the composite solder have improved significantly. During soldering, the intermetallic compound layers are formed due to an interfacial reaction between solder alloy and metal substrate. It is well known that the intermetallic compound is necessary in every solder joint because it determined the strength and wettability of a solder. However, thicker intermetallic is avoided due to brittle nature and poor interfacial bonding of the formation thicker intermetallic layer. A thin, continuous, and uniform intermetallic compound (IMC) layer between a solder and the substrate material is an essential requirement for good bonding [8].

This research discusses the effect of $\mathrm{AC}$ additions on the $\mathrm{Sn}-\mathrm{Cu}-\mathrm{Ni}$ solder alloy in enhancing its solder joint strength. The intermetallic compound and shear strength of the composite solder joint were investigated.

\section{Experiment Details}

Sn-Cu-Ni powder alloys were mixed with different weight percentage $(0,0.25,0.5,0.75$ and 1.0 wt. \% ) of the Activated Carbon in an airtight container using a roller blender rotated at a speed of $200 \mathrm{rpm}$ for 1 hour. $\mathrm{Sn}-\mathrm{Cu}-\mathrm{Ni}$ powders were supplied from Nihon Superior (M) Sdn Bhd with an average particle size of 20-38 $\mu \mathrm{m}$. The mixed powders were then weighed approximately $1 \mathrm{~g}$ each in forming a green compact pellet disc. Each of the solder mixtures was pressed using Specac 15-ton Manual Hydraulic Press and uniaxially compacted in a 12-mm diameter mold. The compacted pallets were sintered with microwave sintering to reach the temperature $185{ }^{\circ} \mathrm{C}$. $\mathrm{SiC}$ was used as the microwave susceptor material [9]. The sintered samples were then placed on $\mathrm{Cu}$ substrate with placing a small amount of no-clean flux and subsequently heated in a reflow oven to form solder joints.

For futher analysis, the reflowed samples were mounted, polished and etched with a solution of $93 \%$ methanol $+5 \% \mathrm{HNO}_{3}+2 \% \mathrm{HCl}$ to reveal a clear microstructure for imaging. Interfacial IMC layer was observed using Optical Microscope (ECLIPSE L300N) and Scanning Electron Microscope (SEM). The IMC thickness measurement was carried out by dividing the IMC area (A) by its length (L). The average thickness of the IMC layer was taken determined at 10 positions of the interface using the micrographs. To determined the solder joint strength, a single-lap shear solder joint sample were prepared by bonding the composite solder to the $\mathrm{Cu}$-substrate (PCB FR-4). The $12 \mathrm{~mm}$ diameter of solder samples with a thickness of approximately $0.5 \mathrm{~mm}$ were sandwiched with the $\mathrm{Cu}$-substrate. The reflow soldering process was used using the $\mathrm{F}_{4} \mathrm{~N}$ reflow oven. The specifications of the shear test were based on the ASTM D1002. Shear tests were then conducted by using Instron Machine.

\section{Result and Discussion}

\subsection{Intermetallic Compound}

Fig. 1 show the thickness for IMC layer of $\mathrm{Sn}-\mathrm{Cu}-\mathrm{Ni}$-xAC composite solder. By increasing the reinforcement addition, the IMC layer thickness showed a decreasing trend. The thinnest IMC layer was achieved with the addition of $1.0 \mathrm{wt}$. \% reinforcement in $\mathrm{Sn}-\mathrm{Cu}-\mathrm{Ni}$ xAC. AC addition has not just reduce the IMC thickness, but has also altered the IMC 
layer shape. The IMC layer has change from needle scallop shaped to continuous shaped as shown in Fig 2. The changes in IMC layer shape (Fig. 3) are considered as desired changes since the needle scallop-shaped induce brittle fracturing at the interface and provides crack thus decreasing the solder joint reliability [10].

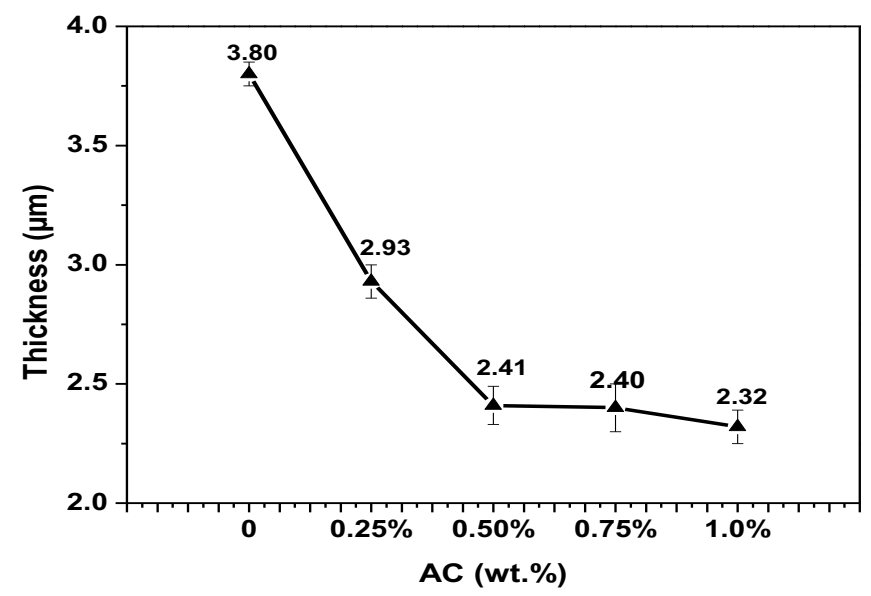

Fig.1. IMC layer thickness of Sn-Cu-Ni-xAC composite solder joint.

The observation was in conjuction with the observation done by S.L.Tay et. al [10]. They found that a scallop-shaped intermetallic layer was formed after reflow but changed to a planar type when Co particle addition in SAC solder. The addition of Ni nanoparticles also influence the thickness and shape of IMC layer as reported by S.L.Tay et al.[11]. They also found the morphology of $\mathrm{Cu}_{6} \mathrm{Sn}_{5}$ IMC changes from a scalloped structure to a planar type after reflow while the growth of $(\mathrm{Cu}, \mathrm{Ni})_{6} \mathrm{Sn}_{5}$ enhanced but reduced in $\mathrm{Cu}_{3} \mathrm{Sn}$ [11]. They suggested that the Co and Ni containing solder entrapped in the IMC layer thus changes the interfacial IMC.

According to the EDX result using line and area scanning mode in Fig. 4 and Table 1, it shows that AC particles exist between solder and substrate interfaces (line 001). Scanning mode (Area 002) also detects the existence of reinforcement particle in that area. It supports that reinforcement particles act to retard the growth of IMC when they distributed homogeneously at the diffusion path for IMC growth.

The formation of IMC layer is mainly due to the diffusion of atoms from the substrate into the solder matrix. Diffusion rates control the IMC growth that solder/IMC interface energies control the coarsening of the IMC grain and nucleation kinetics [12]. IMCs form rapidly at the interface and act as the bonding materials between the solder and the substrate. Due to the present of reinforcement in the solder matrix, it could alter the diffusion rate at the interfacial layer. Reinforcement particles are believed to act as a barrier that block the diffusion of $\mathrm{Cu}$ and $\mathrm{Sn}$ from reacting to each others. 

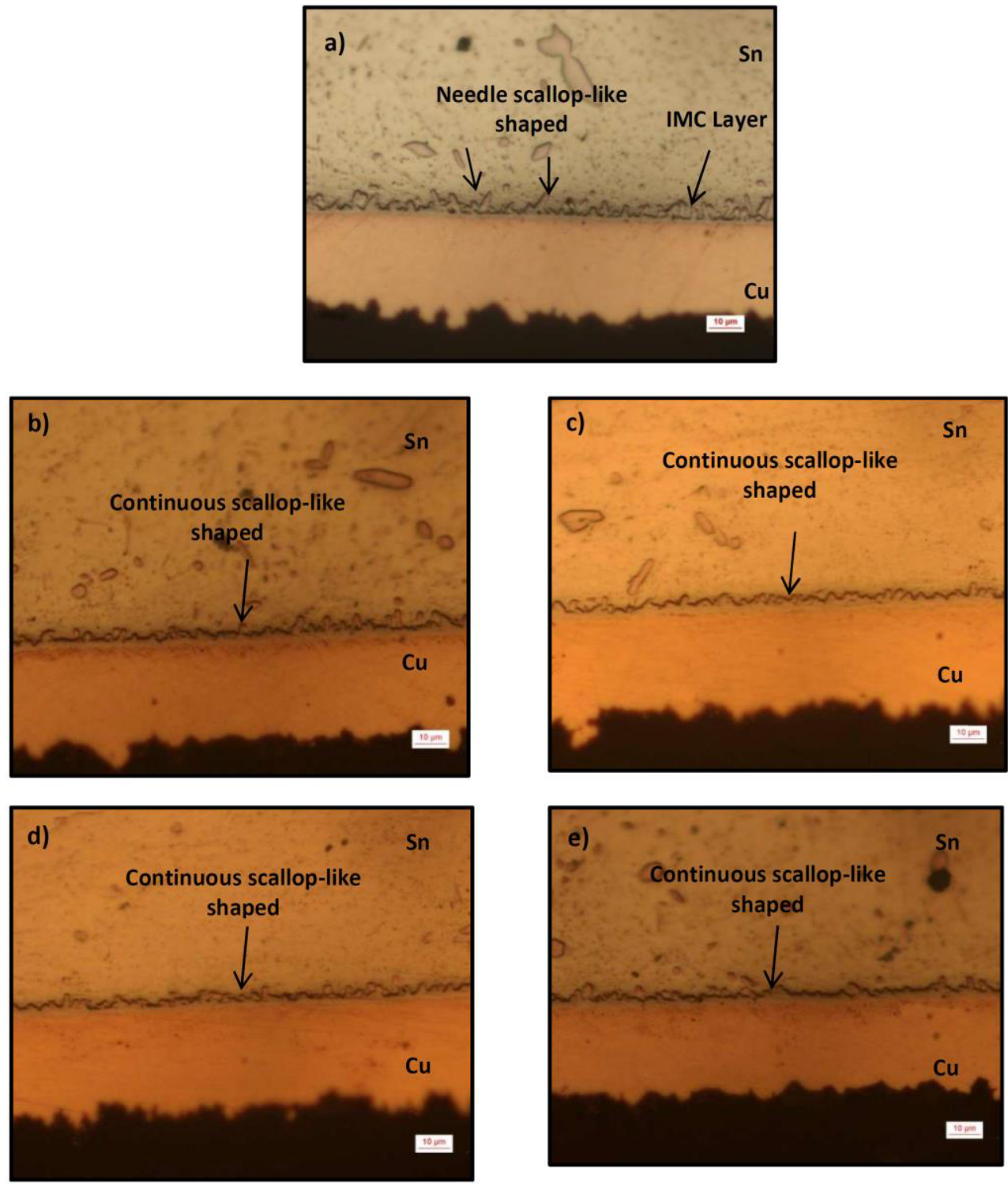

Fig.2. Micrograph of cross-sectional view of interfacial IMC (a) Sn-Cu-Ni, (b) Sn-Cu-Ni-0.25AC, (c) $\mathrm{Sn}-\mathrm{Cu}-\mathrm{Ni}-0.5 \mathrm{AC}$, (d) Sn-Cu-Ni-0.75AC and (e) Sn-Cu-Ni-1AC. 

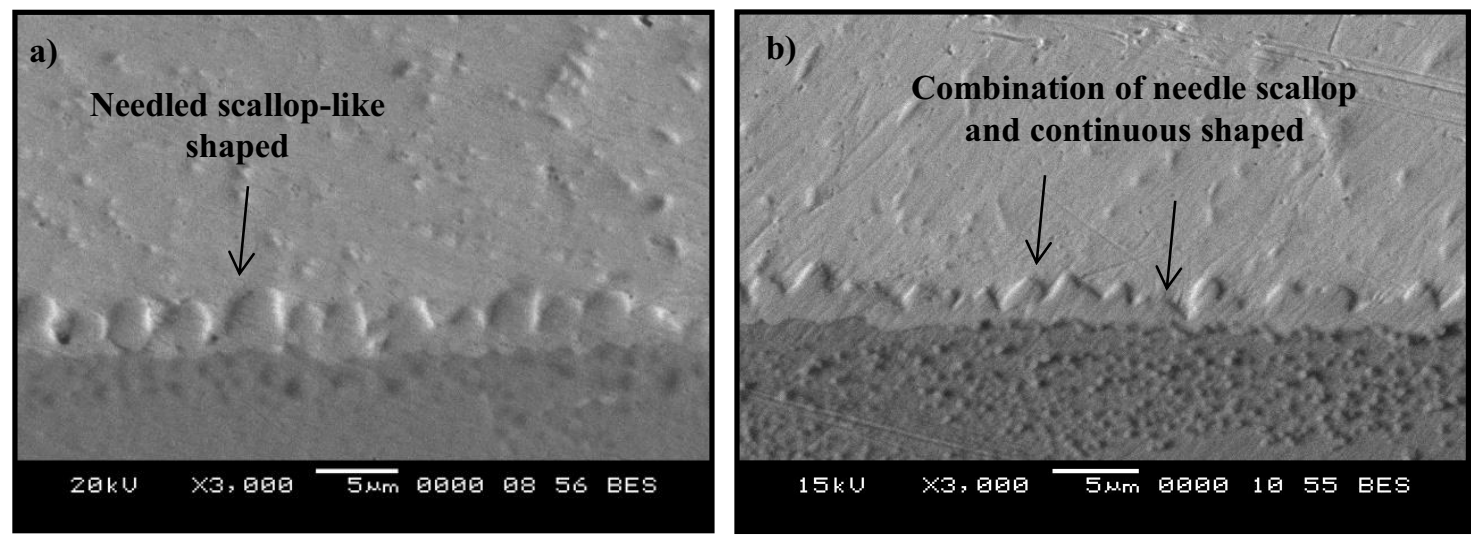

Fig.3. SEM Micrograph of cross-sectional view of interfacial IMC a) Sn-Cu-Ni b) Sn-Cu-Ni-1.0AC.

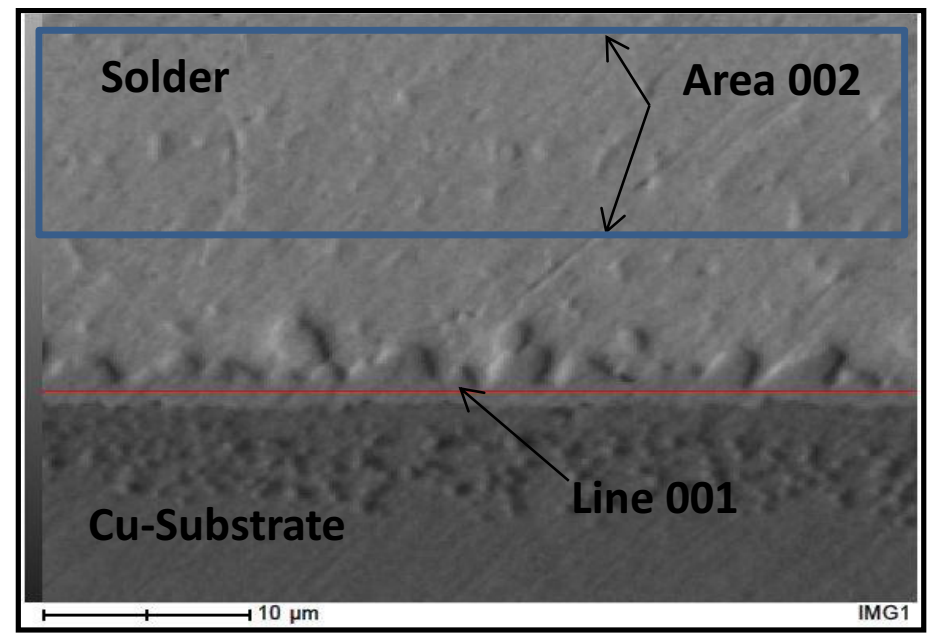

Fig. 4. Cross-sectional view of IMC layer $\mathrm{Sn}-\mathrm{Cu}-\mathrm{Ni}-1.0 \mathrm{AC}$.

Table 1. EDX analysis of IMC layer $\mathrm{Sn}-\mathrm{Cu}-\mathrm{Ni}-1.0 \mathrm{AC}$.

\begin{tabular}{|cccc|}
\hline & Element & $\begin{array}{c}\text { Weight Percent } \\
(\mathbf{\%})\end{array}$ & $\begin{array}{c}\text { Atomic } \\
(\mathbf{\%})\end{array}$ \\
Line 001 & $\mathrm{C}$ & 2.24 & 13.52 \\
& $\mathrm{Sn}$ & 47.71 & 29.22 \\
& $\mathrm{Cu}$ & 50.05 & 57.26 \\
& $\mathrm{C}$ & 1.20 & 10.68 \\
Area 002 & $\mathrm{Sn}$ & 98.23 & 88.37 \\
& $\mathrm{Cu}$ & 0.57 & 0.95 \\
\hline
\end{tabular}




\subsection{Shear strength}

Strength of the solder joint basically depends on the IMC formation at the interface [13]. Although the intermetallic compound is necessary for solder joint, excessive intermetallic thicknessis need to be avoided because of their brittle properties. As shown in Fig. 5, the shear strength value increase linearly with increases weight percentages of AC particles. As the weight percentages of AC approach $1.0 \mathrm{wt}$. \%, the maximum value of shear strength has reached $13.966 \mathrm{MPa}$. The factor that attributed to the increases of shear strength was cause by the decreases of IMC thickness and dislocation interaction to slide or slip. When stress being applied to the composite solder joint, the existence of $\mathrm{AC}$ will resist the grain boundary sliding.

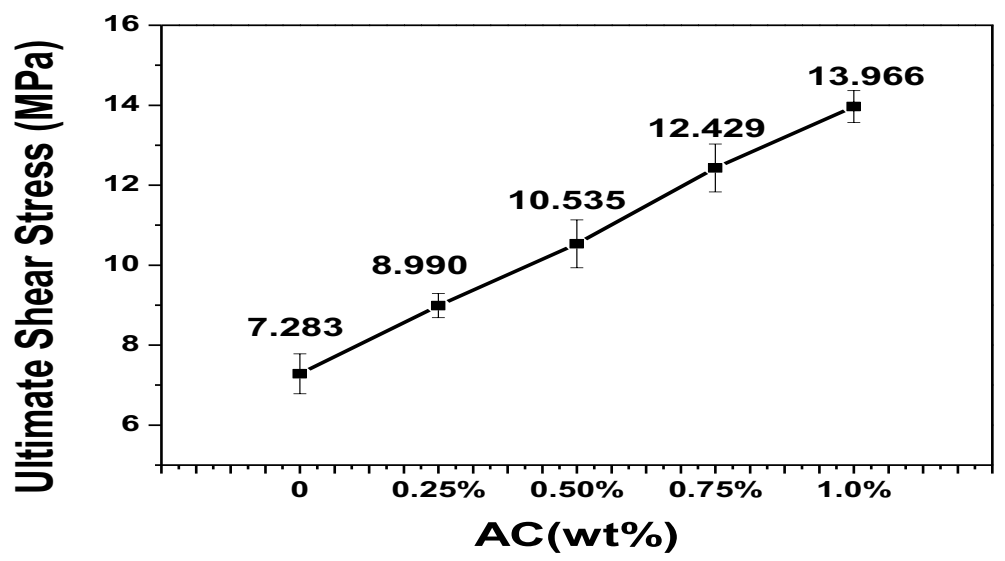

Fig. 5. Shear strength of Sn-Cu-Ni-xAC composite solder joint.

\section{Conclusion}

In this research, the influence of AC particles addition on intermetallic compound and shear strength of $\mathrm{Sn}-\mathrm{Cu}-\mathrm{Ni}$ lead free solder are studied and following conclusion can be made:

a) The addition of $\mathrm{AC}$ as reinforcement reduces the intermetallic compound (IMC) thickness and suggested that $\mathrm{AC}$ act as a barrier to retard the growth of the formation IMC layer.

b) The addition of $\mathrm{AC}$ particle improved the shear strength of the $\mathrm{Sn}-\mathrm{Cu}-\mathrm{Ni} / \mathrm{xAC}$ solder joint.

The authors gratefully acknowledge the financial support from Nihon Superior Co. Ltd., Japan under Grant No. 9008-00003 and the School of Material Engineering, University Malaysia Perlis (UniMAP) for supporting this research effort through materials and facilities. The support of Associate Professor Kazuhiro Nogita from the University of Queensland for his valuable advice throughout this study is greatly appreciated.

\section{References}

1. G. Zeng, S. Xue, L. Zhang, L. Gao, J. Mater. Sci-Mater. El., 22, 565 (2011)

2. T. Ventura, C.M. Gourlay, K. Nogita, T. Nishimura, M. Rappaz, A.K. Dahle, J. Electron Mater., 37, 32 (2008) 
3. Z. Liang, T. Lei, G. Yonghuan, S. Lei, M. Yong, J. Rare Earth, 32, 1184 (2014)

4. Y. Tang, G.Y. Li, Y.C. Pan, Mater. Design, 55, 574 (2014)

5. S.M.L. Nai, J. Wei, M. Gupta, Thin Solid Films, 504(1), 401 (2006)

6. M.I.I. Ramli, N. Saud, M.A.A.M. Salleh, M.N. Derman, R.M. Said, N. Nasir, Appl. Mech. Mater., 754, 518 (2015)

7. M.A.A.M. Salleh, A.M.M. AlBakri, M.H. Zan. Hazizi, F. Somidin, N.F.M. Alui, Z.A. Ahmad, Mat. Sci. Eng. A-Struct., 556, 633(2012)

8. J. Shen, Y.C. Chan, Microelectron Reliab., 49, 223 (2009)

9. S.M.L. Nai, J.V.M. Kuma, M.E. Alam, X.L. Zhong, P. Babaghorbani, M. Gupta, J. Mater. Eng. Perform, 19(3), 335 (2010)

10. S.L. Tay, A.S.M.A. Haseeb, M.R. Johan, Solder Surf. Mt. Tech., 23(1), 10 (2011)

11. S.L. Tay, A.S.M.A. Haseeb, M.R. Johan, P.R. Munroe, M.Z. Quadir, Intermetallics, 33, 8 (2013)

12. L.M. Lee, A.A. Mohamad, Adv. Mater. Sci. Eng., 2013(4), 1(2013)

13. M.O. Alam, H. Lua, C. Bailey, Y.C. Chan, Comp. Mater. Sci., 45, 576 (2009) 